\begin{tabular}{ll}
\multicolumn{2}{c}{ УЧЕНЫЕ ЗАПИСКИ КАЗАНСКОГО УНИВЕРСИТЕТА. } \\
СЕРИЯ ГУМАНИТАРНЫЕ НАУКИ \\
\hline 2021, Т. 163, кн. 4-5 & ISSN 2541-7738 (Print) \\
С. 23-33 & ISSN 2500-2171 (Online)
\end{tabular}

ОРИГИНА ЛЬНАЯ СТАТЬЯ

УдК 811.161 .1

doi: $10.26907 / 2541-7738.2021 .4-5.23-33$

\title{
ТРАЕКТОРИЯ НАУЧНОГО ПУТИ: ПУБЛИКАЦИИ В.А. КОСОВОЙ В «УЧЕНЫХ ЗАПИСКАХ КАЗАНСКОГО УНИВЕРСИТЕТА»
}

\author{
Е.И. Аюпова \\ Казанская православная духовная семинария, г. Казань, 420036, Россия
}

\begin{abstract}
Аннотация
В работе рассматриваются наиболее значимые результаты научных публикаций профессора Казанского федерального университета Веры Алексеевны Косовой в журнале «Ученые записки Казанского университета. Серия Гуманитарные науки». Цель настоящего исследования - выявление важнейших достижений научной мысли безвременно ушедшего от нас выдающегося ученого, нашедших отражение в материалах университетского издания, с которым Вера Алексеевна сотрудничала более 20 лет. Читателю предлагается общая характеристика указанных статей в хронологическом порядке, что позволяет продемонстрировать эволюцию научных интересов В.А. Косовой. Краткому анализу подвергаются тематика, методология, исследовательские выводы изучаемых публикаций. Показано, что в рассматриваемых статьях представлена в основных чертах имеющая большую научную значимость дериватологическая концепция В.А. Косовой, касающаяся вопроса о категориях словообразования и эффективности ономасиологического подхода к изучению словообразовательной семантики. Кроме того, данные публикации содержат ценные методологические наработки, иллюстрирующие авторские принципы анализа феноменов словообразования.
\end{abstract}

Ключевые слова: Вера Алексеевна Косова, «Ученые записки Казанского университета», теория словообразования, словообразовательная категория, анализ словообразовательной семантики

9 марта 2021 года на 61-м году жизни скоропостижно скончалась Вера Алексеевна Косова (1960-2021), доктор филологических наук, профессор кафедры русского языка как иностранного Института филологии Казанского федерального университета. Более 20 лет, с конца 1990-х годов (после возобновления издания «Ученых записок Казанского университета») и до последних своих дней Вера Алексеевна тесно сотрудничала с главным университетским журналом. С «Учеными записками Казанского университета» связаны годы ее плодотворной работы в качестве редактора, рецензента и автора научных текстов. Входила в состав редколлегии журнала «Ученые запискм Казанского университета. Серия Гуманитарные науки», была заместителем главного редактора. В рамках настоящей публикации дается обзор статей, изданных В.А. Косовой (в том числе в соавторстве) в «Ученых записках...». Разумеется, это лишь малая часть 
всего ее научного наследия, однако и здесь, как в капле воды, отражаются важнейшие лингвистические идеи, размышления, открытия талантливого исследователя. За период с 2001 по 2021 г. в «Ученых записках...» вышло 13 статей Веры Алексеевны, что составляет $21.67 \%$ (примерно $1 / 5$ ) от общего числа (60) ее научных статей [1].

Сфера главных исследовательских интересов Веры Алексеевны всегда так или иначе включала словообразование. В первые годы научной деятельности в центре ее внимания были частные вопросы словообразовательной науки: феномен словообразовательного супплетивизма (например, в кругу наименований детенышей животных), соотношение семантического словообразования и многозначности и т. п. В дальнейшем В.А. Косова выходит на уровень теоретического обобщения, к проблеме словообразовательных категорий, и одним из первых шагов в этом направлении стала статья «Деривация и ее место в языковой системе», которая была опубликована в «Ученых записках...» в 1998 г. В этой статье Вера Алексеевна, рассматривая различные точки зрения на термин деривация, обосновывает не только тезис о «деривационной сущности супплетивизма», но и правомерность наиболее широкого представления о деривации, понимаемой как «глобальное языковое явление, имеющее семантическую природу и проявляющееся в диахронии... и в синхронии» [2, с. 175].

Серию ее работ XXI столетия в «Ученых записках...» открывает статья 2006 г. «Категория отвлеченного действия, состояния (nomina actionis) в системе номинативной деривации русского языка». В этой публикации В.А. Косова также затрагивает проблему словообразовательного супплетивизма, подвергая сомнению приводимые Ю.Д. Апресяном примеры этого феномена в сфере nomina actionis (отвлеченных наименований действия или состояния). Свою позицию Вера Алексеевна обосновывает результатами функционального анализа этой категории, рассмотренной в системе номинативной деривации. Вывод ученого логически безупречен и теоретически значим: «Словообразовательная связь глагол - отглагольное отвлеченное существительное не является ни семантически однозначной, ни императивной для русского языка, следовательно, данная номинативно-деривационная категория не обладает свойством последовательной коррелятивности» [3, с. 115]. Это означает, что термин «словообразовательный супплетивизм», подразумевающий единичные исключения при регулярных словообразовательных отношениях, не может быть применим к данной категории имен с непоследовательной коррелятивностью.

В 2007 г., обобщая результаты своей корректорской и редакторской деятельности в «Ученых записках...», В.А. Косова выступила с публикацией по стилистике и культуре речи. В фокусе ее внимания оказался жанр научной статьи в его гуманитарной и естественнонаучной разновидностях. Скрупулезный анализ жанровых признаков научного стиля в отношении статей гуманитарного характера убедительно показал, что в статьях этого типа «проявляется индивидуальный почерк ученого, поэтому в них возможно использование экспрессивновыразительных средств, характерных в большей степени для публицистического стиля» $[4$, с. 233]. Заметим, однако, что все наблюдения, касающиеся субъективности и экспрессии стиля гуманитарной научной статьи, были сделаны исключительно на материале статей по философии. Едва ли такими признаками обладают 
научные тексты по юриспруденции, истории, лингвистике, литературоведению и другим гуманитарным дисциплинам. Можно предположить, что именно в философских статьях, в которых научная мысль неизменно сопряжена с мировоззренческим поиском (то есть объективность - с субъективностью), происходит трансформация жанра научной статьи в сторону индивидуализации и экспрессивизации авторского почерка, а в статьях других областей гуманитарного знания этот феномен представлен в гораздо меньшей степени.

В 2008 г. в «Ученых записках...» выходит статья В.А. Косовой «Ономасиологический подход как основа исследования словообразовательной категоризации действительности». В этой статье казанская исследовательница вплотную подходит к определению важнейшего дериватологического понятия - словообразовательной категории. Сопоставляя точки зрения различных лингвистов (Е.А. Земской, Е.С. Кубряковой, Ю.С. Азарх и др.), она делает закономерный вывод: только при ономасиологическом подходе, то есть при сопоставлении различных номинативных средств языка, выражающих сходное значение, можно говорить о наличии или отсутствии соотнесенности рассматриваемого значения с соответствующей словообразовательной категорией.

Такой подход позволяет сформулировать критерии выделения словообразовательных категорий и принципы их анализа по следующей схеме: «Прежде всего необходимо выявить все средства выражения интересующего исследователя номинативного значения, которыми располагает языковая система. Далее все однословные номинативные единицы с заданным значением анализируются с позиций производности - непроизводности, на основании чего делается вывод о характере категории в плане соотносительности ее единиц... В том случае, если анализируемое значение нашло в языке собственно словообразовательную реализацию, то есть передается лишь производными словами (наличие единичных непроизводных слов, которые можно квалифицировать как супплетивные средства, для установления типа категории несущественно), необходимо выявить словообразовательную модель, формирующую доминантный словообразовательный тип в составе данной категории, и определить семантический объем соответствующего форманта» [5, с. 222-223].

Исключительно важной в теоретическом отношении является и предложенная В.А. Косовой классификация языковых категорий, позволяющая четко отделить друг от друга словообразовательные, лексико-словообразовательные и чисто лексические категории (так называемые тематические и лексико-семантические группы): указанные категории можно назвать соответственно соотносительныли, частично (потенциально) соотносительными и несоотносительнылмu. Именно этот метод анализа словообразовательных категорий в их постоянном сопоставлении с иными номинативными средствами языка сумела реализовать в дальнейшем Вера Алексеевна вместе со своими учениками, которые продолжают перспективные и актуальные исследования в этом направлении.

В 2009 г. в «Ученых записках...» была напечатана статья «Семантическая категоризация лексикона: совмещение методов лексикологии и словообразования», в которой обоснована комплексная методика определения состава лексикосемантических категорий. На примере глаголов с семантикой мышления и чувственного восприятия Вера Алексеевна убедительно показывает недостаточность 
применения компонентного анализа лексического значения при выявлении состава названных категорий: именно анализ словообразовательного потенциала базовых лексем позволяет существенно дополнить представления об исследуемых категориях и включить в их состав несколько неучтенных единиц, ведь «знание особенностей производного слова вооружает исследователей дополнительными механизмами адекватного структурирования лексико-семантической системы языка» [6, с. 255].

В 2010 г. В.А. Косова печатает в «Ученых записках...» свою программную статью «Словообразовательная категория: формирование понятия и основные направления исследования». Эта статья носит обзорно-аналитический характер (в библиографическом списке насчитывается 54 единицы!) и предлагает читателю историю осмысления понятия словообразовательная категория в отечественном языкознании начиная с работ В.В. Виноградова и заканчивая научными конгрессами и диссертационными исследованиями начала XXI столетия. В статье кратко, но четко характеризуется вклад в развитие этого словообразовательного вопроса таких ученых, как В.В. Виноградов, Ю.С. Азарх, Р.С. Манучарян, Е.С. Кубрякова, А.М. Зализняк, Е.А. Земская и др. Материалы статьи наглядно демонстрируют этапы процесса формирования представлений о словообразовательной категории, выявляют дискуссионные аспекты данной проблемы: широкое и узкое понимание словообразовательной категории, соотношение этого понятия с другими терминами теории деривации, принципы выделения категориальных значений и под. Данная статья В.А. Косовой, безусловно, имеет высокую теоретическую значимость как обобщение накопившегося опыта и знаменует собой переход к следующему этапу - когнитивно ориентированным ономасиологическим исследованиям словообразовательных категорий, имеющим целью «создание непротиворечивой теории словообразовательной категориальности, а также описание категориального строя русского словообразования» [7, с. 208].

В этом русле продолжаются и собственные исследования Веры Алексеевны во втором десятилетии нынешнего века: в 2011 г. в журнале «Ученые записки Казанского университета» появляется ее новая статья по данной проблеме «Словообразовательная категория и ее категориальное окружение». Здесь также прослеживается история вопроса, сопоставляются различные точки зрения на категории языка и мышления и выявляется специфика словообразовательных категорий. По мнению ученого, «вывод об универсальности мыслительного содержания словообразовательных категорий равносилен заключению об отсутствии у них специфической понятийной зоны: эти категории являются способом языковой репрезентации обобщенных (в большей или меньшей степени) понятийных смыслов, которые могут передаваться в данном языке также грамматическими и лексическими средствами. Специфична сама форма представления мыслительного содержания в производном слове: это всегда сочетание, комбинация двух (реже - трех и более) пропозиционально связанных концептов» [8, с. 174].

Представляется, что это очень важный тезис, позволяющий говорить о специфике и самостоятельности словообразовательных категорий в соотношении с другими когнитивными и языковыми категориями: словообразовательные категории отличает не характер выражаемого смысла, а обязательная одновременная актуализация двух (и более) концептов, выражаемых производящим 
и производным словами. Природа словообразовательной категории предполагает эту содержательную и формальную бинарность, акцентирование не только самих смыслов, но и их взаимосвязи. Покажем на примере: непроизводное слово волк не обладает названной концептуальной бинарностью, так как выражает только одно понятие «волк» ('хищное животное семейства псовых'). А производное слово волчонок принципиально бинарно, поскольку отражает концепты «волк» и «детеныш» в их взаимосвязи, то есть представляет собой некое смысловое объединение, комбинацию этих концептов. Важно, что данная бинарность присутствует и на смысловом, и на формальном уровне (производящая основа и формант). Высокая регулярность выражения этого значения именно при помощи производных слов позволяет считать категорию названий детенышей животных словообразовательной (в терминологии В.А. Косовой также «соотносительной»), а не лексической («несоотносительной») или лексико-словообразовательной («частично соотносительной»). Поэтому древние несоотносительные номинации типа жеребёнок, поросёнок, телёнок принято квалифицировать как феномен словообразовательного супплетивизма: будучи формально не выраженной в производящей основе, смысловая связь с концептом соответствующего взрослого животного (то есть содержательная бинарность) в сознании носителей языка устойчива и несомненна.

В 2012 г. в «Ученых записках...» была опубликована статья В.А. Косовой в соавторстве с аспиранткой Чжао Сяохэн «Категория наименований лица по роду деятельности в русском жаргоне». Данная публикация носит главным образом практический характер, поскольку знакомит читателя с результатами анализа жаргонных номинаций человека по роду его деятельности, выявленных в словарях современного русского сленга. Здесь почти не затрагиваются вопросы словообразования (хотя это тоже очень любопытный аспект исследования, ведь многие приведенные жаргонные наименования являются мотивированными и, следовательно, производными), зато приводятся статистические данные по категоризации лексической группы на основании тех или иных интегральных и дифференциальных признаков. В ходе анализа выявляются такие специфические черты рассматриваемой группы, как стихийность и непоследовательность, склонность к автономинации (наименование «своих» членов микросоциума) и дискурсивная ограниченность (наименование партнеров по коммуникации), дробность субкатегоризации (появление отсутствующих в литературном языке номинаций в отдельных значимых сферах), «обилие лексем с оценочно-характеризующим компонентом значения» и реализация «функции самовыражения субъекта речевой деятельности» [9, с. 169].

В 2013 г. у Веры Алексеевны снова выходит глубокая общетеоретическая статья «Деривационно-семантическая типология словообразовательных категорий». Эта публикация носит проблемный характер, так как предлагает собственную точку зрения автора на важные спорные вопросы в типологизации словообразовательных категорий. В центре внимания находится ономасиологический подход к разграничению этих категорий, обоснованный чешским исследователем М. Докулилом, который предложил выделить мутационные, модификационные и транспозиционные категории. Дискуссионный характер имеют проблемы выделения а) транспозиции как особого словообразовательного феномена 
и б) смешанных категорий, совмещающих признаки вышеназванных базовых разновидностей.

Вдумчивое отношение к этим проблемам позволяет В.А. Косовой найти логически непротиворечивое решение в рамках традиционной типологии. В частности, она предлагает рассматривать транспозицию как тип словообразовательных категорий, в которых происходит «перевод грамматической (частеречной) семы базового слова в доминантную (ядерную) позицию собственно лексической зоны значения деривата» [10, с. 149]. При этом среди транспозиционных категорий могут выделяться разновидности с «добавочными смыслами» (например, экспрессивно-оценочными, ср. бег и беготня), но это не препятствует их принадлежности к транспозиции. Такой подход снимает и вопрос о «смешанных» категориях, поскольку выделение модификационных категорий имеет смысл лишь при сохранении тождества ядерных сем и становится невозможным при наличии мутационных или транспозиционных преобразований в семантической структуре слова.

Всестороннее теоретическое осмысление вопроса о словообразовательных категориях, отраженное в многочисленных публикациях, позволило Вере Алексеевне выйти на новый уровень научно-исследовательского творчества: в 2014 г. по этой теме ею была защищена докторская диссертация, основные положения которой представлены в монографии «Словообразовательные категории русского языка: проблемы теории» [11]. С этого времени опытный ученый много времени и сил отдает активному и плодотворному научному взаимодействию с аспирантами: в 2013-2020 гг. под ее руководством было защищено шесть кандидатских диссертаций, а в сентябре 2021 г. (уже после кончины Веры Алексеевны) - еще две. И в «Ученых записках...» появляются статьи В.А. Косовой в соавторстве с аспирантами, отражающие результаты их совместного научного творчества.

Так, в 2016 г. выходит в свет статья В.А. Косовой и Е.А. Маклеевой «О функциональном анализе морфем, или Сколько в русском языке суффиксов -ушк-». В данной работе представлена и теоретически обоснована авторская методика функционального анализа словообразовательных морфем, а также продемонстрирована ее эффективность на примере анализа разновидностей суффикса -ушк- в русском языке. Применяемый подход к изучению формантов можно с уверенностью назвать комплексным, так как он учитывает различные функциональные характеристики словообразовательных аффиксов: деривационносемантическую спецификацию, коммуникативно-речевые функции, текстопорождающий потенциал, стилистическую маркированность и т. п. (см. [12, с. 13451346]). Представленный материал анализа убедительно показывает действенность данной авторской методики, которая позволяет составить многомерный портрет аффикса и вписать изучаемые форманты и производные лексемы в различные языковые парадигмы.

Другой пример анализа словообразовательных единиц представляет вышедшая в 2017 г. в соавторстве с аспиранткой А.В. Трофимовой статья «Русские префиксальные глаголы с позиционным значением как средство вербализации пространственного мышления». Здесь ставится иная задача: рассмотреть развитие деривационной семантики, приводящее к формированию тех или иных переносных 
значений. В статье это направление исследований обозначено как «композиционная семантика» [13, с. 1231], поскольку оно изучает именно сочетаемость производящей основы и форманта и описывает модели их взаимодействия. Четкий компонентный анализ с привлечением словарных дефиниций, текстовых иллюстраций и материалов диахронических исследований позволил авторам выявить и описать несколько моделей синтеза форманта и основы по схеме «префикс с пространственной семантикой + статальный позиционный глагол» (предстоять, надлежать и под.). Было обнаружено, что при взаимодействии основы и аффикса их базовые пространственные и позиционные семы могут нейтрализоваться, что приводит к развитию у производных глаголов бытийной, социальной, речевой и пр. семантики. Безусловно, продемонстрированный тип анализа словообразовательных единиц не только дает возможность описать пути развития значений в производных словах, но и затрагивает когнитивные процессы и механизмы, а также древнейшие ментальные характеристики человека, членящего и познающего мир посредством словообразовательных номинаций. Вне всякого сомнения, исследования такого рода очень перспективны, они имеют выход в лингвистическую когнитивистику и лингвокультурологию.

В том же номере журнала в 2017 г. В.А. Косова в соавторстве с коллегами Л.Р. Ахмеровой и Е.С. Палехой опубликовала статью к 80-летнему юбилею профессора Эмилии Агафоновны Балалыкиной, научного наставника целого поколения казанских лингвистов. Эта публикация носит научно-биографический и справочно-библиографический характер и свидетельствует не только о научных заслугах Эмилии Агафоновны, но и об исследовательской преемственности между учителем и учениками (см. [14, с. 1073-1075]). Именно проф. Э.А. Балалыкина является автором фундаментальных работ по русскому и сопоставительному словообразованию на диахроническом и синхроническом материале: «Научные достижения Эмилии Агафоновны весомы и относятся прежде всего к области русского (современного и исторического) и сравнительно-исторического словообразования» [14, с. 1069]. Под ее руководством в 1995 г. В.А. Косова защитила кандидатскую диссертацию «Супплетивизм в номинативно-деривационной системе современного русского языка», которая через 19 лет выросла в фундаментальное докторское исследование.

Последние публикации Веры Алексеевны в «Ученых записках...» также были сделаны в соавторстве с аспирантами - как результат совместных научных исследований учителя и учеников. В 2018 г. вышла в свет статья В.А. Косовой и Го Линь «Разграничение семантически близких глаголов: потенциал квантитативных методов». В этой работе в центре внимания оказываются не словообразовательные характеристики, а лексическая семантика и сочетаемость. Именно анализ этих параметров, подкрепленный статистическими данными, позволяет разграничить два близких по смыслу глагола восприятия - ощущать и чувствовать. Было обнаружено, что первый из них характеризуется связью «с областью сенсорного восприятия», тогда как второй «обладает более широким диапазоном лексической сочетаемости» и имеет «значительно более высокую частотность употребления в речи», «тяготея к описанию внутренних (физических и эмоциональных) состояний» [15, с. 1189]. 
В 2020 г. была опубликована статья В.А. Косовой и Лю Фанфан «Отсубстантивные суффиксальные прилагательные с семантикой интенсивности в русском языке: системно-функциональный подход». В данной работе изучается словообразовательная категория интенсивности с применением двух методов - системноструктурного изучения лексики и функционального анализа, возможности которого были показаны в предыдущих публикациях. Статья носит сопоставительный характер, так как посвящена сравнению адъективных моделей на -acmbiŭ,-ambiй, -истый схожей семантики: выявляются черты сходства и различия между моделями в плане выражения значения степени признака, специфики производящей основы, продуктивности, стилистической маркированности и под. Вывод, подтверждаемый статистическими данными Национального корпуса русского языка, четко противопоставляет эти модели по ряду параметров: «Очевидная мотивационная и стилистическая дистрибуция обозначенных словообразовательных средств с наличием зоны пересечения позволяет констатировать их системный параллелизм» $[16$, с. 43$]$.

Подводя итоги, отметим, что проанализированные нами публикации В.А. Косовой в «Ученых записках Казанского университета», являющиеся лишь небольшой частью ее научных трудов, убедительно демонстрируют весомые теоретические и практические достижения и серьезный исследовательский потенциал безвременно ушедшего от нас талантливого ученого. В этих статьях представлены и глубокие размышления Веры Алексеевны о дискуссионных вопросах словообразования, и образцы применения авторских методик анализа лингвистического материала, которые могут служить подспорьем для будущих поколений лингвистов и являют собой драгоценный вклад в развитие перспективных направлений современного языкознания.

\section{Литература}

1. Косова Вера Алексеевна: Результативность работы. Персональная страница сотрудника КФУ // Казанский (Приволжский) федеральный университет. - URL: https://kpfu.ru/main?p_id=11116\&p_lang=\&p_type=9\&p_pub_type=20, свободный.

2. Косова В.А. Деривация и ее место в языковой системе // Учен. зап. Казан. ун-та. 1998. - Т. 135. - C. 171-175.

3. Косова B.A. Категория отвлеченного действия, состояния (nomina actionis) в системе номинативной деривации русского языка // Учен. зап. Казан. ун-та. Сер. Гуманит. науки. - 2006. - Т. 148, кн. 2. - С. 110-118.

4. Косова В.A. Трансформация жанра научной статьи или выделение жанровых разновидностей? // Учен. зап. Казан. ун-та. Сер. Гуманит. науки. - 2007. - Т. 149, кн. 1. C. 224-234.

5. Косова В.А. Ономасиологический подход как основа исследования словообразовательной категоризации действительности // Учен. зап. Казан. ун-та. Сер. Гуманит. науки. -2008 . - Т. 150, кн. 6. - С. 217-224.

6. Косова В.А. Семантическая категоризация лексикона: совмещение методов лексикологии и словообразования // Учен. зап. Казан. ун-та. Сер. Гуманит. науки. -2009. Т. 151, кн. 3. - С. 248-256.

7. Косова B.A. Словообразовательная категория: формирование понятия и основные направления исследования // Учен. зап. Казан. ун-та. Сер. Гуманит. науки. $-2010 .-$ Т. 152, кн. 6. - C. 199-212. 
8. Косова В.А. Словообразовательная категория и ее категориальное окружение // Учен. зап. Казан. ун-та. Сер. Гуманит. науки. - 2011. - Т. 153, кн. 6. - С. 167-183.

9. Косова В.А., Чжао C. Категория наименований лица по роду деятельности в русском жаргоне // Учен. зап. Казан. ун-та. Сер. Гуманит. науки. - 2012. - Т. 154, кн. 5. C. $164-170$.

10. Косова В.А. Деривационно-семантическая типология словообразовательных категорий // Учен. зап. Казан. ун-та. Сер. Гуманит. науки. - 2013. - Т. 155, кн. 5. C. $141-151$.

11. Косова В.А. Словообразовательные категории русского языка: проблемы теории. Казань: Новое знание, 2014. - 204 с.

12. Косова В.А., Маклеева Е.А. О функциональном анализе морфем, или Сколько в русском языке суффиксов -ушк- // Учен. зап. Казан. ун-та. Сер. Гуманит. науки. - 2016. Т. 158, кн. 5. - С. 1338-1358.

13. Трофимова A.В., Косова В.А. Русские префиксальные глаголы с позиционным значением как средство вербализации пространственного мышления // Учен. зап. Казан. ун-та. Сер. Гуманит. науки. - 2017. - Т. 159, кн. 5. - С. 1231-1243.

14. Ахмерова Л.Р., Косова В.А., Палеха Е.С. Широта ума, сила воображения и активность души - вот что такое гений // Учен. зап. Казан. ун-та. Сер. Гуманит. науки. 2017. - Т. 159, кн. 5. - С. 1061-1078.

15. Го Л., Косова В.А. Разграничение семантически близких глаголов: потенциал квантитативных методов // Учен. зап. Казан. ун-та. Сер. Гуманит. науки. - 2018. - Т. 160, кн. 5. - С. 1176-1192.

16. Лю Ф., Косова В.А. Отсубстантивные суффиксальные прилагательные с семантикой интенсивности в русском языке: системно-функциональный подход // Учен. зап. Казан. ун-та. Сер. Гуманит. науки. - 2020. - Т. 162, кн. 5. - С. 33-47. - doi: 10.26907/2541-7738.2020.5.33-47.

Аюпова Елена Ильдаровна, кандидат филологических наук, доцент кафедры филологии

Казанская православная духовная семинария

ул. Челюскина, д. 31 а, г. Казань, 420036, Россия

E-mail: eayupova@yandex.ru 
UCHENYE ZAPISKI KAZANSKOGO UNIVERSITETA. SERIYA GUMANITARNYE NAUKI (Proceedings of Kazan University. Humanities Series)

2021, vol. 163, no. 4-5, pp. 23-33

ORIGINAL ARTICLE

doi: $10.26907 / 2541-7738.2021 .4-5.23-33$

\author{
Navigating the Academic Path: \\ V.A. Kosova's Publications in "Uchenye Zapiski Kazanskogo Universiteta" \\ E.I. Ayupova \\ Kazan Theological Seminary, Kazan, 420036 Russia \\ E-mail: eayupova@yandex.ru
}

Received August 16, 2021

\begin{abstract}
This article is a tribute to an outstanding researcher, mentor, and personality that was Kazan Federal University Professor Vera Alekseevna Kosova. Her most interesting and important scientific publications from "Uchenye Zapiski Kazanskogo Universiteta. Seriya Gumanitarnye Nauki" (Proceedings of Kazan University. Humanities Series") are considered. Before her untimely death in 2021, V.A. Kosova devoted more than 20 years to collaborating with the journal and played an active role in its history. Here, the above-mentioned articles are reviewed in chronological order, thereby casting light on the evolution of V.A Kosova's research interests. The subject of her works, the methods applied, and the major conclusions are briefly analyzed. It is shown that the articles under consideration develop V.A. Kosova's derivatological concept, which concerns the problems of word-formation categories and the effectiveness of the onomasiological approach to the study of word-formation semantics. Notably, this concept has been considered to be of high scientific relevance by many researchers. The articles also contain invaluable data on V.A. Kosova's methodological approach to the analysis of wordformation phenomena.
\end{abstract}

Keywords: Vera Alekseevna Kosova, "Uchenye Zapiski Kazanskogo Universiteta", theory of word formation, word-formation category, analysis of word-formation semantics

\title{
References
}

1. Kosova Vera Alekseevna: Professional results. Profile of KFU employee. Kazan Federal University. Available at: https://kpfu.ru/main?p_id=11116\&p_lang=\&p_type=9\&p_pub_type=20. (In Russian)

2. Kosova V.A. Derivation and its role in the language System. Uchenye Zapiski Kazanskogo Universiteta. Seriya Gumanitarnye Nauki, 1998, vol. 135, pp. 171-175. (In Russian)

3. Kosova V.A. The category of abstract action, state (nomina actionis) in nomination derivation system of the Russian language. Uchenye Zapiski Kazanskogo Universiteta. Seriya Gumanitarnye Nauki, 2006, vol. 148, no. 2, pp. 110-118. (In Russian)

4. Kosova V.A. Transformation of the genre of scientific article or genre specification? Uchenye Zapiski Kazanskogo Universiteta. Seriya Gumanitarnye Nauki, 2007, vol. 149, no. 1, pp. 224-234. (In Russian)

5. Kosova V.A. Onomasiological approach as a basis for researching word-formational reality categorization. Uchenye Zapiski Kazanskogo Universiteta. Seriya Gumanitarnye Nauki, 2008, vol. 150, no. 6, pp. 217-224. (In Russian)

6. Kosova V.A. Semantic categorization of lexicon: combination of lexicological and word-building methods. Uchenye Zapiski Kazanskogo Universiteta. Seriya Gumanitarnye Nauki, 2009, vol. 151, no. 3, pp. 248-256. (In Russian) 
7. Kosova V.A. Word-formation category: The development of the notion and basic lines of investigation. Uchenye Zapiski Kazanskogo Universiteta. Seriya Gumanitarnye Nauki, 2010, vol. 152, no. 6, pp. 199-212. (In Russian)

8. Kosova V.A. Word-formation category and its categorial environment. Uchenye Zapiski Kazanskogo Universiteta. Seriya Gumanitarnye Nauki, 2011, vol. 153, no. 6, pp. 167-183. (In Russian)

9. Kosova V.A., Zhao X. The category of personal nouns denoting occupations in Russian slang. Uchenye Zapiski Kazanskogo Universiteta. Seriya Gumanitarnye Nauki, 2012, vol. 154, no. 5, pp. 164-170. (In Russian)

10. Kosova V.A. Derivational and semantic typology of word-formation categories. Uchenye Zapiski Kazanskogo Universiteta. Seriya Gumanitarnye Nauki, 2013, vol. 155, no. 5, pp. 141-151. (In Russian)

11. Kosova V.A. Slovoobrazovatel'nye lategorii russkogo yazyka: problemy teorii [Derivational Categories of the Russian Language: Theory Problems]. Kazan, Nov. Znanie, 2014. 204 p. (In Russian)

12. Kosova V.A., Makleeva E.A. On the functional analysis of morphemes or how many -ushk- suffixes there are in the Russian language. Uchenye Zapiski Kazanskogo Universiteta. Seriya Gumanitarnye Nauki, 2016, vol. 158, no. 5, pp. 1338-1358. (In Russian)

13. Trofimova A.V., Kosova V.A. Russian prefixal posture verbs as a means of spatial thinking verbalization. Uchenye Zapiski Kazanskogo Universiteta. Seriya Gumanitarnye Nauki, 2017, vol. 159, no. 5, pp. 1231-1243. (In Russian)

14. Akhmerova L.R., Kosova V.A., Palekha E.S. Breadth of mind, strong imagination, and active soul make up a genius (on the birth anniversary of Emiliya Agafonovna Balalykina). Uchenye Zapiski Kazanskogo Universiteta. Seriya Gumanitarnye Nauki, 2017, vol. 159, no. 5, pp. 1061-1078. (In Russian)

15. Guo L., Kosova V.A. Differentiation of semantically close verbs: The potential of quantitative methods. Uchenye Zapiski Kazanskogo Universiteta. Seriya Gumanitarnye Nauki, 2018, vol. 160, no. 5, pp. 1176-1192. (In Russian)

16. Liu F., Kosova V.A. Substantive suffixal adjectives with the semantics of intensity in the Russian language: A systemic functional approach. Uchenye Zapiski Kazanskogo Universiteta. Seriya Gumanitarnye Nauki, 2020, vol. 162, no. 5, pp. 33-47. doi: 10.26907/25417738.2020.5.33-47. (In Russian)

/ Для цитирования: Аюпова Е.И. Траектория научного пути: публикации В.А. Косовой в «Ученых записках Казанского университета» // Учен. зап. Казан. ун-та. Сер. Гуманит. науки. - 2021. - Т. 163, кн. 4-5. - С. 23-33. - doi: 10.26907/2541-7738.2021.4-5.23-33.

For citation: Ayupova E.I. Navigating the academic path: V.A. Kosova's publications in "Uchenye Zapiski Kazanskogo Universiteta". Uchenye Zapiski Kazanskogo Universiteta. Seriya Gumanitarnye Nauki, 2021, vol. 163, no. 4-5, pp. 23-33. doi: 10.26907/25417738.2021.4-5.23-33. (In Russian) 